\title{
Cell Membrane-Coated Electrospun Fibers Enhance Keratinocytes Growth Through Cell-Type Specific Interactions
}

Wai Hon Chooi ${ }^{\ddagger \mathrm{a}}$, Quanbin Dong ${ }^{\ddagger}$, Jeremy Zhi Yan Low ${ }^{\mathrm{c}}$, Clement Yuen ${ }^{\mathrm{a}}$, Jiah Shin Chin

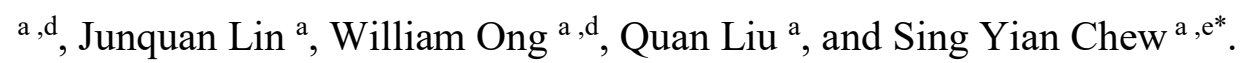

a School of Chemical \& Biomedical Engineering, Nanyang Technological University, Singapore.

${ }^{b}$ Department of Cardiology, The Second Affiliated Hospital of Nanchang University, China.

${ }^{c}$ School of Biological Sciences, Nanyang Technological University, Singapore.

d NTU Institute of Health Technologies, Interdisciplinary Graduate School, Nanyang Technological University, Singapore.

e Lee Kong Chian School of Medicine, Nanyang Technological University, Singapore.

\section{Corresponding Author}

*Sing Yian Chew: sychew@ntu.edu.sg. 


\section{Materials}

Polycaprolactone (PCL, average $\mathrm{Mw}=80000)$, 2,2,2-trifluoroethanol (TFE), poly-D-Lysine (PDL), and Triton-X 100 were purchased from Sigma-Aldrich (USA). Paraformaldehyde (PFA, 4\%) was purchased from Santa Cruz Biotechnology (USA). All other reagents were purchased from ThermoFisher (USA).

\section{Electrospun fiber scaffolds fabrication}

Electrospun fiber scaffolds were prepared according to our previous protocol with slight modification. ${ }^{1-3}$ Briefly, PCL solution was prepared by dissolving in TFE overnight before electrospinning. Coverslips $(\varnothing 18 \mathrm{~mm})$ were then adhered onto a rotation wheel by carbon tapes. The PCL solution was then loaded into a syringe and dispensed by a syringe pump, with opposite voltages applied to the blunt needle tip and rotating collector. The specific parameters for obtaining aligned fibers of different diameters are presented in Table S1. Silicone glue was then applied around the coverslip edge to create a $1 \mathrm{~cm}^{2}$ area of fibers on the coverslips. The scaffolds were then irradiated by UV for 30 min followed by incubation in sterile $70 \%$ ethanol for 10 min. The scaffolds were then washed thrice with sterile deionized $\mathrm{H}_{2} \mathrm{O}$ and kept in deionized $\mathrm{H}_{2} \mathrm{O}$ until coating.

To measure fiber diameters, the electrospun scaffolds were sputter-coated with gold at $10 \mathrm{~mA}$ for $120 \mathrm{~s}$ and then observed under an SEM (JOEL JSM-6390LA) at a $10-\mathrm{kV}$ accelerating voltage. The average fiber diameters were obtained by measuring at least 100 fibers per sample by using ImageJ $(\mathrm{NIH})$.

\section{T3 fibroblasts culture and cell membrane preparation}

3T3 fibroblasts were a generous gift from Professor David Becker at Nanyang Technological University. The 3T3 fibroblasts were cultured in DMEM with GlutaMAX, supplemented with $10 \%$ fetal bovine serum and $1 \%$ penicillin/streptomycin. The medium change was performed every 3 days. Passage 20-22 fibroblasts were used to prepare cell membrane in this study. 
When the 3T3 fibroblasts were approaching 90\% confluency, the cells were washed by Hanks' Balanced Salt Solution (HBSS) and then labeled by Wheat Germ Agglutinin, Alexa Fluor 555 Conjugate (WGA-AF555) at $5 \mu \mathrm{g} / \mathrm{mL}$ (approximately $2 \mathrm{~mL}$ per $10-\mathrm{cm}$ culture dish) for $10 \mathrm{~min}$ at $37^{\circ} \mathrm{C}$. Thereafter, the cells were washed twice with PBS and then incubated in $0.5 \mathrm{mM}$ EDTA for $10 \mathrm{~min}$ at $37^{\circ} \mathrm{C}$. The detached cells were then centrifuged at $200 \times \mathrm{g}$ for $5 \mathrm{~min}$. Hypotonic lysis buffer $(20 \mathrm{mM}$ Tris $-\mathrm{HCl} \mathrm{pH}$ $7.5,10 \mathrm{mM} \mathrm{KCl}, 2 \mathrm{mM} \mathrm{MgCl}$, protease inhibitor cocktail) was then added to lyse the cells. The cells were incubated in the lysis buffer at room temperature for $15 \mathrm{~min}$ and the cell lysates were frozen at $-20^{\circ} \mathrm{C}$ until further processing. To assist cell membrane disruption, a handheld electric homogenizer (Fisherbrand FS7495400000) was used. Thereafter, the cell lysate was centrifuged at $20,000 \times \mathrm{g}$ for $20 \mathrm{~min}$ and the supernatant was collected and centrifuged at 100,000 $\times \mathrm{g}$ for $45 \mathrm{~min}$. The pelleted cell membrane was then collected by resuspending in $0.6 \mathrm{~mL}$ PBS and stored at $4{ }^{\circ} \mathrm{C}$. As there are various proteins in the cell membrane, BCA assay was carried out to quantify the amount of cell membrane protein according to the manufacturer's protocol. Although this may not represent the true value of the membrane quantity, it can reduce the difference between each experiment and ensure the repeatability of the experiment. The yield of the purified cell membrane protein was in the range of $22-110 \mu \mathrm{g}$ per 10$\mathrm{cm}$ culture dish of confluent 3 T3 fibroblasts.

To coat the cell membrane on the fibers, the cell membrane solution was diluted into different concentrations ( 1 to $20 \mu \mathrm{g} / \mathrm{mL}$ ) by PBS. Following that, the cell membrane solutions were sonicated in a bath sonicator $(37 \mathrm{kHz}, 280 \mathrm{~W})$ for $5 \mathrm{~min}$. Immediately after that, $100 \mu \mathrm{L}$ of the cell membrane solution was added to each scaffold and incubated for $30 \mathrm{~min}$ at room temperature. After that, the scaffolds were washed once with PBS and fixed for further characterization or seeded with cells. For scaffolds that are pre-coated with PDL, fibers were pre-coated with $100 \mu \mathrm{g} / \mathrm{mL} P D L$ for $1 \mathrm{~h}$ at $37^{\circ} \mathrm{C}$ and washed once with $\mathrm{DI}_{2} \mathrm{O}$ before coated with cell membrane.

\section{Fluorescence microscopy}

After coating with cell membrane, the scaffolds were washed once with PBS and imaged under an epifluorescence microscope (Leica DMI8). Brightfield and fluorescence images were taken to observe the fluorescence signal of WGA-AF555 on 
the fibers. For high magnification images, scaffolds were fixed with 4\% PFA for $10 \mathrm{~min}$ at room temperature and then washed three times with PBS. The scaffolds were then mounted onto glass coverslips and imaged under a confocal microscope (Carl Zeiss LSM800). Images were taken at $63 x$ magnification. For quantification of the fluorescence intensity, 10 images were taken for each sample at $20 \times$ magnification. The intensity was then quantified by ImageJ. The experiments were repeated at least 3 times with different scaffolds.

\section{Water contact angle measurement}

The wettability of the fiber scaffolds with or without cell membrane coating was assessed by water contact angle measurements. ${ }^{26}$ Immediately after sonication, 100 $\mu \mathrm{L}$ of the cell membrane solution $(10 \mu \mathrm{g} / \mathrm{mL})$ was added to each scaffold and incubated for 30 min at $37^{\circ} \mathrm{C}$ (cell membrane-coating group: CM), whereas PBS incubation was adopted as the negative control (no treatment group: NT). After that, the scaffolds were washed once with PBS and then dried for $1 \mathrm{~h}$ at $25^{\circ} \mathrm{C}$ for water contact angle detection. $2 \mu \mathrm{L}$ of DI water was dropped onto the scaffold surface, and the results were recorded by the contact angle analyzer (KRUSS DSA25). The experiments were repeated 3 times.

\section{Raman spectroscopy}

A micro-Raman system (innoRam-785S, B\&W TEK, US) was employed to acquire the Raman spectra of scaffolds with and without cell membrane. These two samples were prepared by electrospinning scaffolds on two sheets of aluminum foil and one was subsequently coated with cell membrane $(1 \mu \mathrm{g} / \mathrm{mL})$. In the Raman measurement, both samples were respectively illuminated with a 785-nm laser at an excitation power of $234.1 \mathrm{~mW}$ focused by a $20 \times$ objective lens, and the Raman signals emitted from the sample were collected by the same objective for analysis. Each detected spectrum (spectral resolution of $4 \mathrm{~cm}^{-1}$ ) was collected with an exposure time of $20 \mathrm{~s}$ and accumulated for 4 times. An average spectrum was obtained from 5 random locations correspondingly at the centre and the edge for each sample with a standard deviation smaller than $10 \%$. Noted that the raw data was baseline subtracted and smoothed with a five-point window moving average, followed by fluorescence background subtraction to produce the final spectrum. 
Cell attachment and proliferation on 3T3 cell membrane coated scaffolds

In order to demonstrate the bio-functionality of the scaffolds, human keratinocyte cell line (HaCat cells) were seeded on the 3T3 cell membrane coated scaffolds. The HaCaT cells were a generous gift from Professor David Becker and were cultured in DMEM with GlutaMAX, supplemented with $10 \%$ fetal bovine serum, and $1 \%$ penicillin/streptomycin. The medium change was performed every 3 days. Passage 5-7 HaCaT cells were used for experiments in this study and were seeded on the scaffold at a density of 15,000 cells $\mathrm{cm}^{-2}$ in $100 \mu \mathrm{L}$ full culture medium for $2 \mathrm{~h}$. They were then supplemented with $900 \mu \mathrm{L}$ medium and kept in a humidified incubator at $37{ }^{\circ} \mathrm{C}$ with $5 \% \mathrm{CO}_{2}$. To assess the effects of cell membrane coating on cell attachment, the cell-seeded scaffolds were washed and fixed with $4 \%$ PFA at $2 \mathrm{~h}$ and $24 \mathrm{~h}$ post-seeding. Reduced serum (1\%) and serum-free $(0 \%)$ medium groups were also included to avoid the masking effect by the serum proteins that were present in the full medium. Cell proliferation was observed by culturing the cells for longer durations and fixed at Day 3, 7, 10, and 14. Thereafter, the cell-seeded scaffolds were permeabilized with $0.1 \%$ Triton- $X$ for $15 \mathrm{~min}$ at room temperature followed by actin staining using Alexa Fluor 488 phalloidin and nuclei staining with DAPI. Fluorescent images were acquired with an epifluorescence microscope (Leica DMI8) and analyzed using Image $(\mathrm{NIH})$. In each group, over 10 images from at least 3 scaffolds were taken and quantified. Cell number per area (ROI: $896 \times 668 \mu \mathrm{m}$ ) on the scaffolds were counted for the $2 \mathrm{~h}$ samples. As the cells started to grow in clusters from $24 \mathrm{~h}$ onwards and it was difficult to count the cell number accurately. Hence, cell growth at other time points was quantified by total cell area per ROI.

\section{Functional effect of different cell membranes on HaCaT cell growth}

To further investigate whether the effect of 3 T3 cell membrane coating on $\mathrm{HaCaT}$ cell growth was specific, cell membranes of red blood cells (RBC) were prepared according to published protocol. ${ }^{4}$ Briefly, the whole blood was collected from SD rats (8-12 weeks) and then centrifuged at $800 \times \mathrm{g}$ for $5 \mathrm{~min}$ at $4{ }^{\circ} \mathrm{C}$ to remove the serum and buffy coat. The RBCs were then suspended in $0.25 \times$ PBS for 20 min in an ice bath. Finally, the cell membranes of RBC were collected at $800 \times \mathrm{g}$ for $5 \mathrm{~min}$ at $4{ }^{\circ} \mathrm{C}$ and quantified as mentioned above. Thereafter, $\mathrm{HaCaT}$ cells were seeded on uncoated (NT), 3T3 cell membrane-coated (3T3), and RBC membrane-coated (RBC) 
scaffolds and cultured for 7 days. The samples were fixed, stained, imaged, and quantified for cell area as mentioned above.

Statistical analysis

All data were analyzed with GraphPad Prism 7 (GraphPad Software, USA). Outlier analysis was performed to exclude significant outliers from the subsequent analyses. After checking for variance homogeneity, One-way ANOVA followed by Tukey's post hoc tests or Student's t-test was used for comparisons between multiple or two independent variables respectively. Otherwise, Kruskal-Wallis and Mann Whitney $\mathrm{U}$ tests were used.

\section{References}

1.Chin J S, Chooi W H, Wang H, Ong W, Leong K W, Chew S Y, Acta Biomater., 2019, 90, 60-70.

2.Ong W, Lin J, Bechler M E, Wang K, Wang M, Ffrench-Constant C, Chew S Y, Acta Biomater., 2018, 75, 152-160.

3.Zhang K, Chooi W H, Liu S, Chin J S, Murray A, Nizetic D, Cheng D, Chew S Y, Biomaterials, 2020, 256, 120225.

4. Hu C M, Fang R H, Luk B T, Chen K N, Carpenter C, Gao W, Zhang K, Zhang L, Nanoscale, 2013, 5(7), 2664-2668. 
Table S1. Parameters for electrospinning PCL fibers.

\begin{tabular}{ccccc}
\hline Diameter $(\mathbf{n m})$ & $\mathbf{2 2 0} \pm \mathbf{8 2}$ & $\mathbf{4 6 7} \pm \mathbf{2 3 0}$ & $\mathbf{9 3 9} \pm \mathbf{3 2 1}$ & $\mathbf{2 0 8 7} \mathbf{5 8 4}$ \\
\hline PCL concentration (wt\%) & $12 \%$ & $8 \%$ & $12 \%$ & $14 \%$ \\
Solvent & TFE:Acetic & & & \\
Needle & acid $=1: 9$ & TFE & TFE & TFE \\
Flow rate $(\mathbf{m L} / \mathbf{h})$ & $22 \mathrm{G}$ & $21 \mathrm{G}$ & $21 \mathrm{G}$ & $21 \mathrm{G}$ \\
Distance $(\mathbf{c m})$ & 0.2 & 0.5 & 1 & 2 \\
Rotating speed $(\mathbf{r p m})$ & 12 & 12 & 12 & 12 \\
Voltage $(\mathbf{k V})$ & $+8 /-4$ & $+8 /-4$ & $+4 /-4$ & $+4 /-4$ \\
\hline
\end{tabular}




\section{Surface charge of PCL fibers}

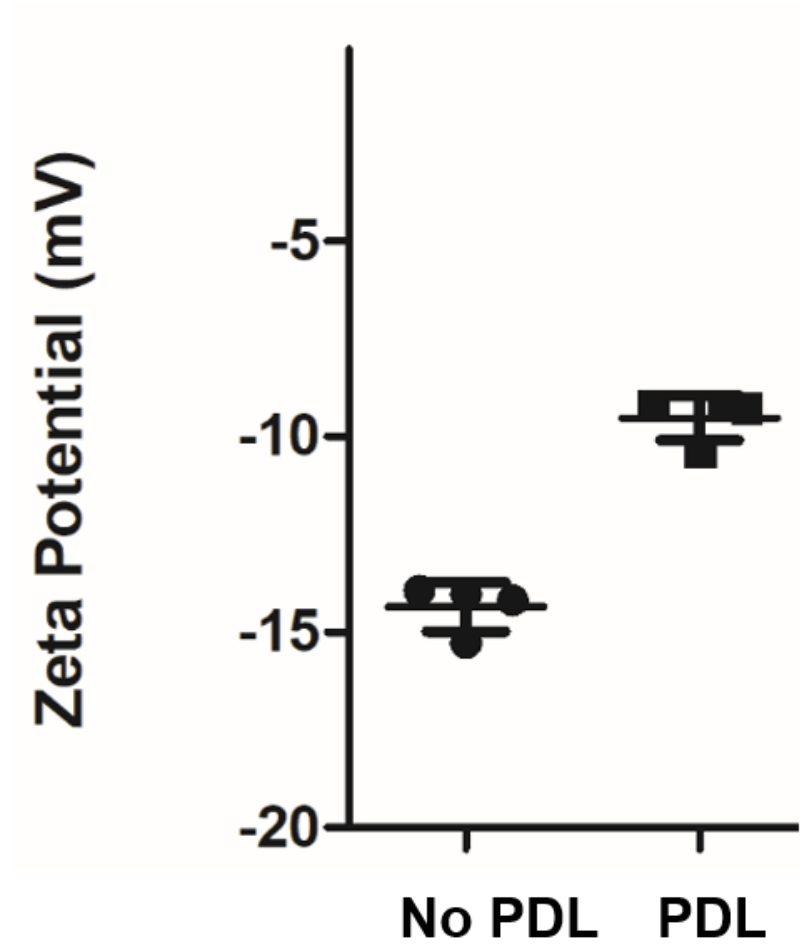

Figure S1. Surface charge of PCL fibers measured by zeta potential shows that PDL coating changed the surface of the PCL fibers to be less negatively-charged. $n=4$ scaffolds per group. Surface potentials were measured using an Anton Paar SurPASS 3 equipped with $\mathrm{pH}$ and conductivity electrodes and autotitrator. For each pair of samples, the gap was adjusted to $100-120 \mu \mathrm{m}$ and $0.001 \mathrm{M} \mathrm{KCl}$ was used as the electrolyte. 

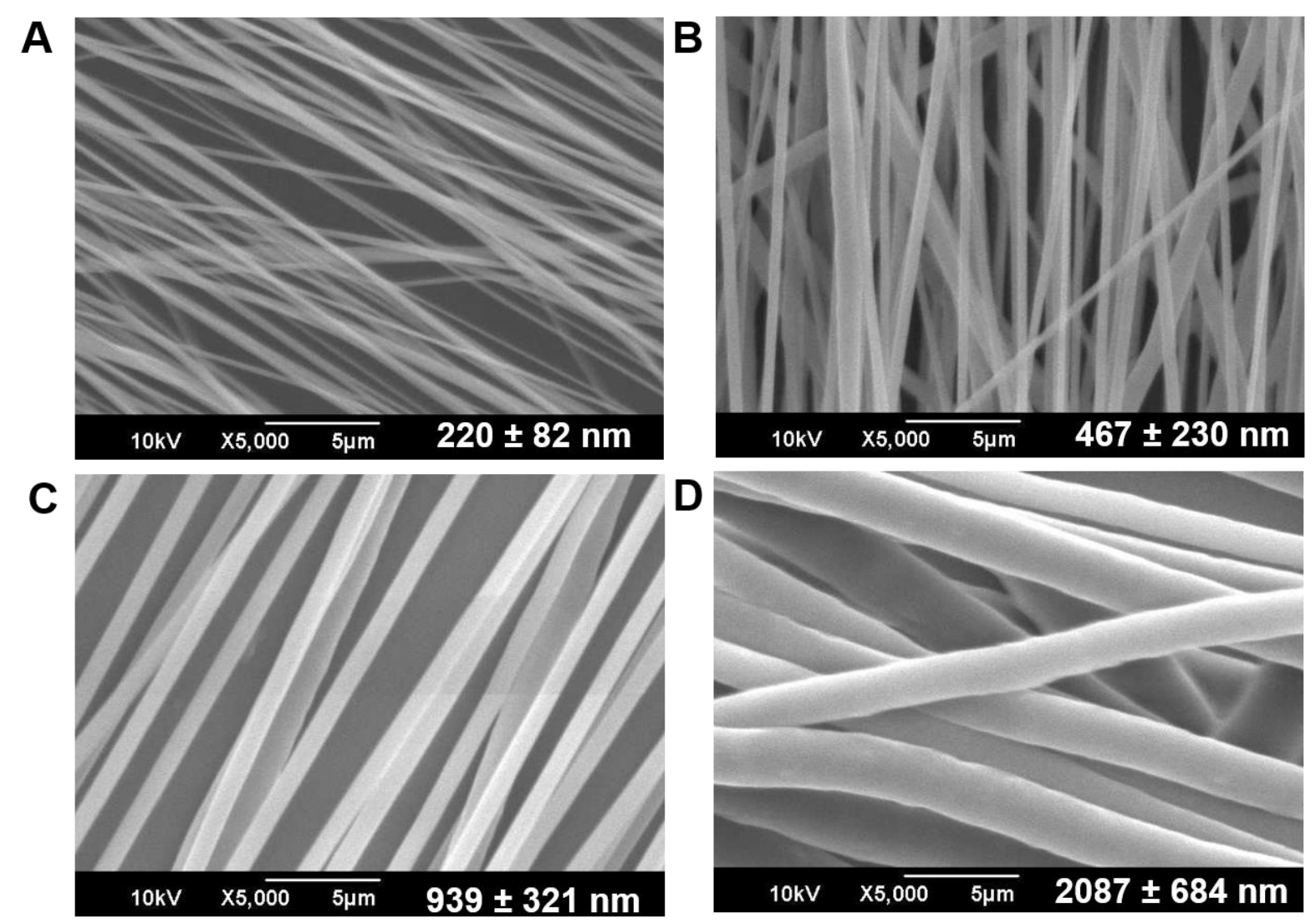

Figure S2. SEM images of aligned electrospun fibers of different diameters: (A) 220 nm, (B) $467 \mathrm{~nm}$, (C) $939 \mathrm{~nm}$, and (D) $2087 \mathrm{~nm}$. 


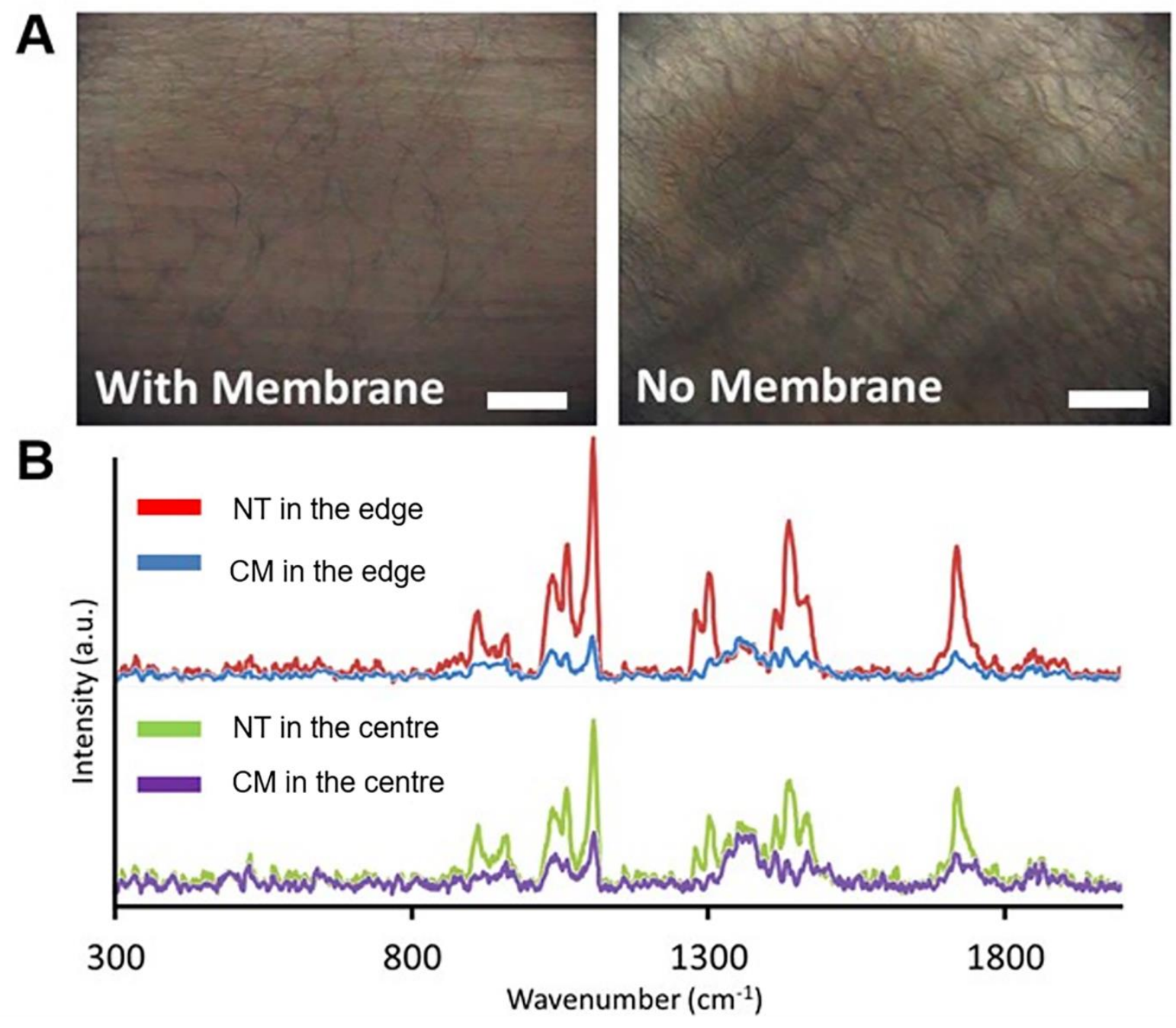

Figure S3. Raman results showing that $3 \mathrm{~T} 3$ cell membrane-coated $\mathrm{PCL}$ fibers rendered a lower Raman intensity comparing with uncoated PCL fiber. (A) Image of fibers with and without 3T3 cell membrane coating. Scale bar: $100 \mu \mathrm{m}$. (B) Representative Raman spectra of fibers with and without 3 T3 cell membrane coating acquired correspondingly at the centre and the edge of the sample, NT: no treatment (PBS only), CM: 3T3 cell membrane coated. 


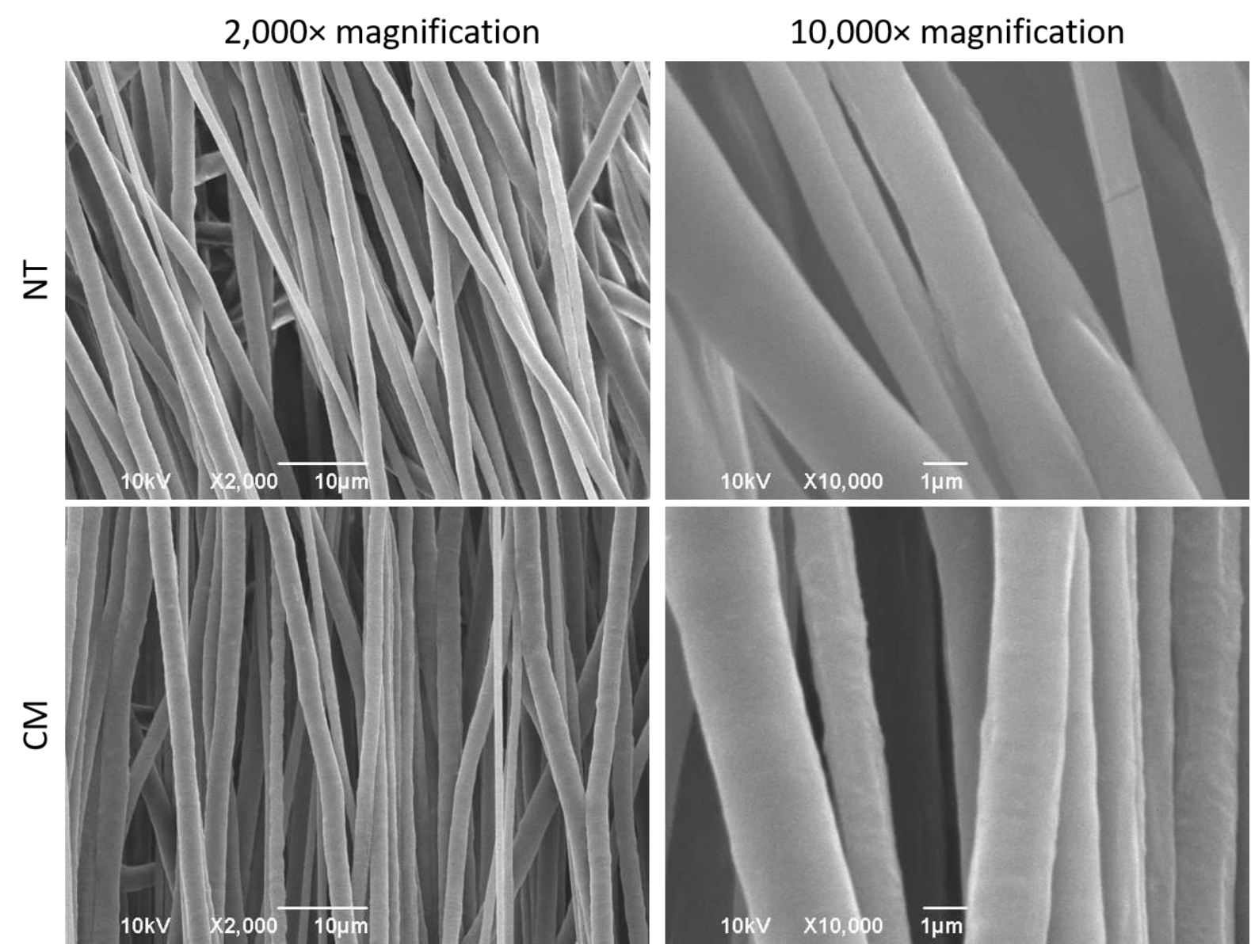

Figure S4. SEM images showing that Cell membrane coating did not affect the gross morphology of the electrospun fibers, NT: no treatment (PBS only), CM: 3T3 cell membrane coated. 
Differential Interference Contrast

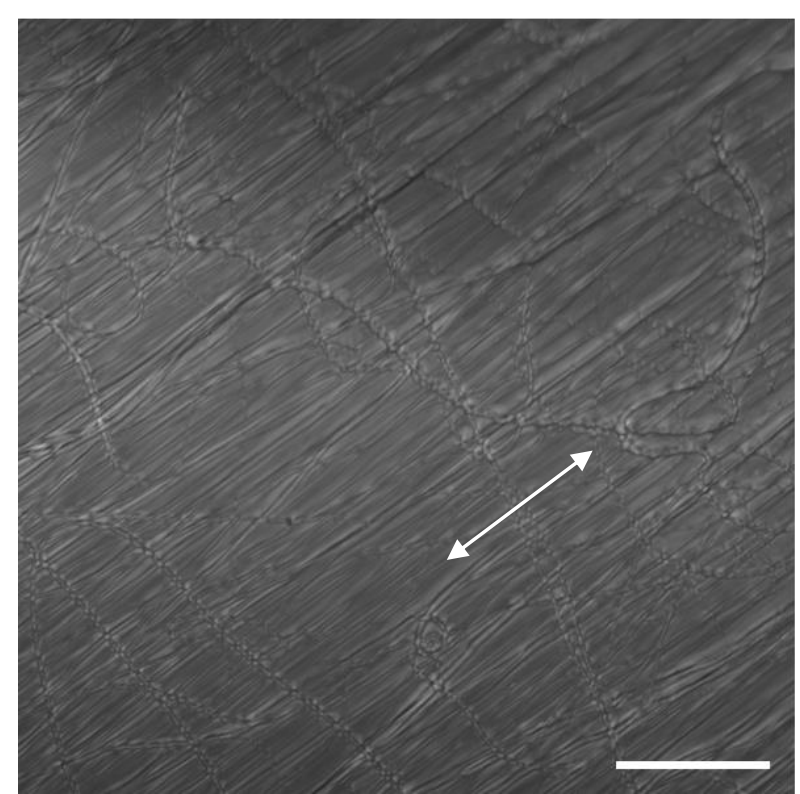

WGA-AF555

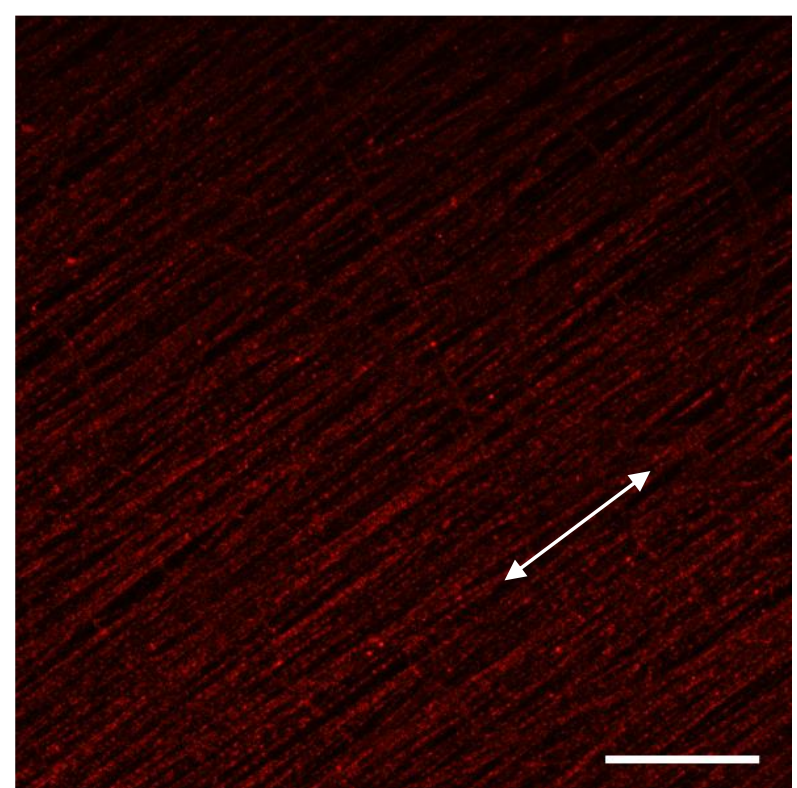

Figure S5. WGA-AF555 labeled 3T3 cell membrane coated fibers $\left(1 \mu \mathrm{g} / \mathrm{cm}^{2}\right)$ showing clear fiber alignment. Scale bar: $20 \mu \mathrm{m}$. White arrows indicate fiber alignment. Images were taken using a Carl Zeiss LSM800 confocal microscope and a 63× objective. 

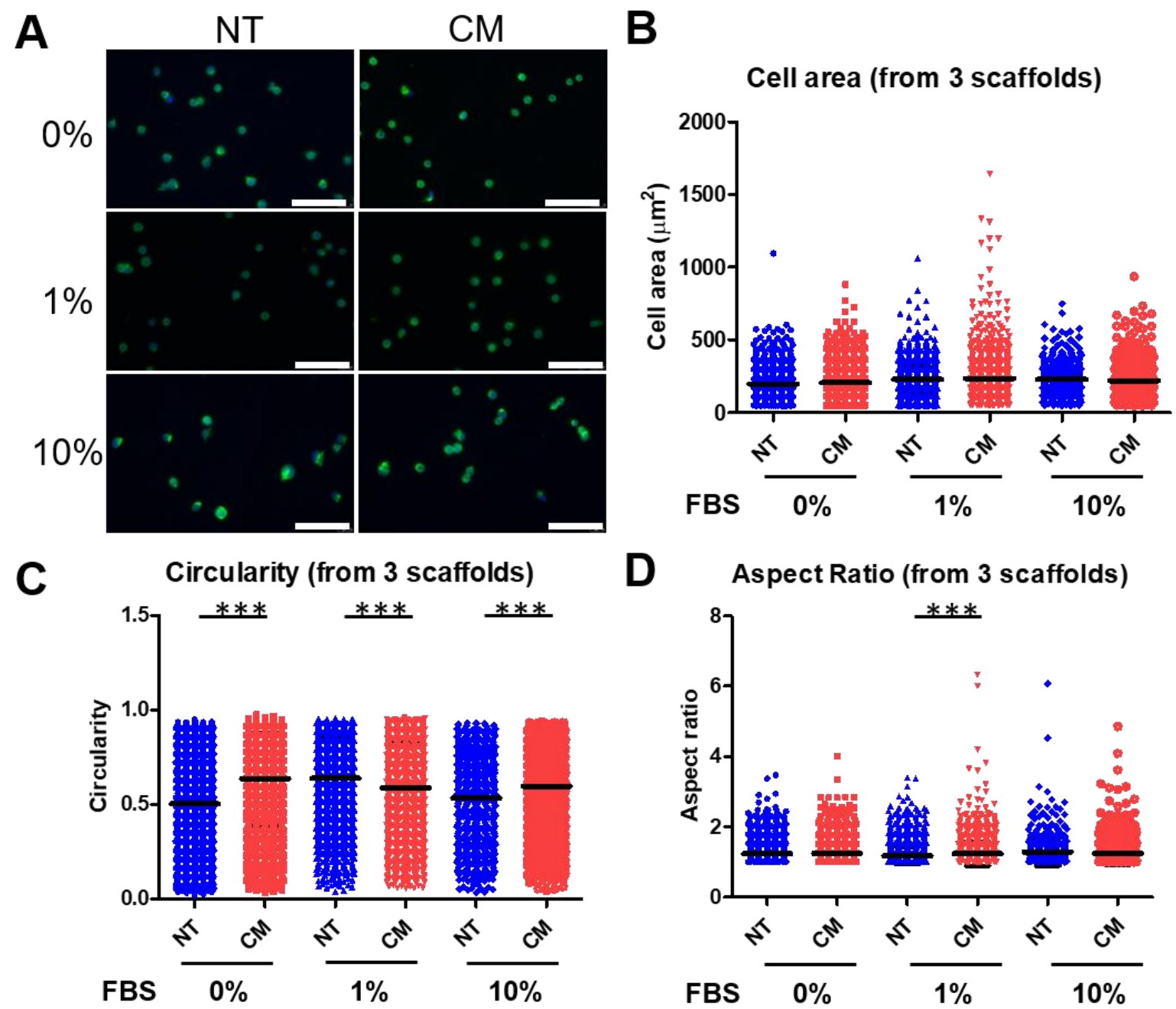

D Aspect Ratio (from 3 scaffolds)

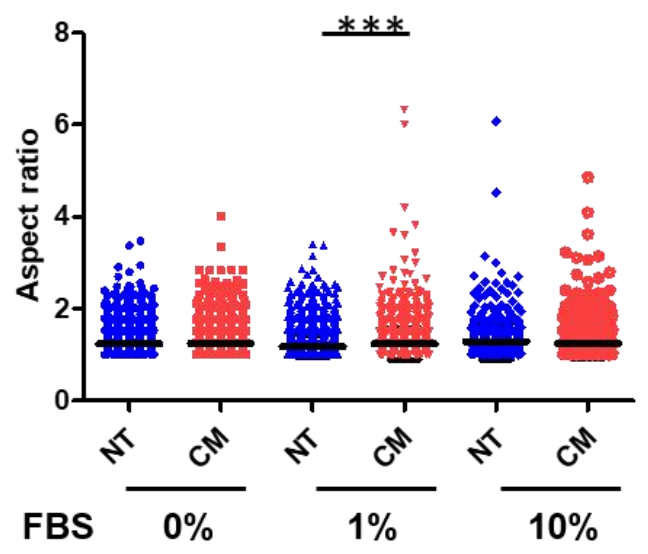

Figure S6: Moderate cell shape changes at $2 \mathrm{~h}$ post-seeding with cell membrane coating. (A) Images were taken at 20x magnification. Green: Phalloidin-AF488 staining of actin, blue: DAPI. NT: no treatment (PBS only), CM: cell membrane coated, FBS: different amounts of fetal bovine serum supplemented in the culture medium. Scale bar: $100 \mu \mathrm{m}$. (B) Cell area of individual cells from different groups. (C) Circularity of individual cells from different groups. (D) Aspect ratio of individual cells from different groups. $n>200$ cells from 3 scaffolds, ${ }^{* * *}: p<0.001$. 